\title{
Ketersediaan Sarana dan Prasarana PJOK di Sekolah Dasar
}

\author{
I KT. B. P. Candra Giri Cahya ${ }^{1 *}$, I Gusti Lanang Agung Parwata², Made Aguswijaya ${ }^{3}$ id \\ ${ }^{123}$ Prodi Pendidikan Jasmani Kesehatan dan Rekreasi, Jurusan Pendidikan Olahraga, Fakultas Olahrga dan Kesehatan, \\ Universitas Pendidikan Ganesha, Singaraja, Bali \\ *Corresponding author: candra88giri@gmai.com
}

\begin{abstract}
Abstrak
Kurangnya sarana dan prasarana dalam menunjang proses pembelajaran sangat berpengrauh terhadap motivasi serta hasil belajar siswa. Sehingga diperlukan sarana dan prasarana yang lengkap pada tiap sekolah. Tujuan yang ingin di capai dalam penelitian ini adalah untuk mengetahui ketersediaan dan kondisi sarana dan prasarana dalam pembelajaran PJOK di SD Negeri se-Kecamatan Tembuku Kabupaten Bangli. Penelitian ini berjenis deskriptif, yaitu penelitian yang bertujuan menjelaskan dan menggambarkan peristiwa secara natural yang dilakukan dengan menganalisis data dan hasil dari data tersebut dengan menggunakan hasil data yang diperoleh dari proses yang sudah berlangsung. Penelitian ini menggunakan instrument PDPJOI. Dalam penelitian ini menggunakan metode deskriftif dengan menggunakan lembar instrument PPJOI. Berdasarkan observasi yang telah dilakukan dari penelitian survei sarana dan prasarana PJOK yang dilakukan di SD Negeri se-Kecamatan Tembuku Kabupaten Bangli. Dapat disimpulkan bahwa mengenai sarana dan prasarana yang ada di SD Negeri se-Kecamatan Tembuku Kabupaten Bangli , masih kategori kurang "D" sekolah masih belum memiliki sarana dan prasarana yang cukup memadai sehingga tidak mampu menunjang proses pembelajaran PJOK itu berlangsung.
\end{abstract}

Kata Kunci: Sarana dan Prasarana PJOK, Instrumen PDPJOI

\section{Abstract}

The lack of facilities and infrastructure in supporting the learning process greatly affects student motivation and learning outcomes. So that complete facilities and infrastructure are needed in each school. The goal to be achieved in this study is to determine the availability and condition of facilities and infrastructure in PJOK learning in State Elementary Schools throughout Kecamatan Tembuku, Kabupaten Bangli. The results of the data by using the results of the data obtained from the ongoing process. This study uses the PDPJOI instrument. This research uses a descriptive method using the PPJOI instrument sheet. Based on the observations that have been made from the survey research of PJOK facilities and infrastructure conducted in SD Tembuku District, Bangli Regency. It can be concluded that regarding the existing facilities and infrastructure in SD Tembuku District, Bangli Regency, the school still has the "D" category. The school still does not have adequate facilities and infrastructure, so it cannot support the PJOK learning process taking place.

Keywords: PJOK Facilities and Infrastructure, PDPJOI Instruments

\section{History:}

Received: 24 Maret 2020

Revised: 15 April 2020

Accepted: 17 Mei 2020

Published: 7 Juni 2020
Publisher: Undiksha Press

Licensed: This work is licensed under

a Creative Commons Attribution 3.0 License

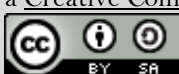




\section{Pendahuluan}

Pendidikan adalah proses pembelajaran wawasan, keterampilan, dan perilaku seseorang yang diturunkan dari satu genereasi ke generasi selanjutnya melalui pengalaman, pengajaran, dan penelitian. Adapun yang menyatakan bahwa pendidikan yaitu suatu prilaku sadar yang dilaksanakan secara sistematis dan berprosedur dalam mencapai suasana pembelajaran agar para siswa dapat mengembangkan potensi dirinya. Sistem pendidikan di Indonesia setiap tahun terus mengalami pembaharuan guna untuk meningkatkan mutu pendidikan itu sendiri. Pendidikan PJOK merupakan suatu bidang kajian yang sangat luas dan sangat dalam artinya. Definisi PJOK berarti berbagai ungkapan dan kalimat. Namun dasarnya sama, yang artinya jelas, maka PJOK menggunakan alat fisik untuk mengembangkan kelengkapan manusia. Pada kaitan ini dimaksudkan maka dari fisik, mental dan emosional pun ikut terkembangkan, apalagi dalam penekanan yang cukup dalam. Menurut (Sudarmono, 2013) tujuan dari PJOK tidak hanya untuk mengembangkan dari segi jasmani saja, akan tetapi juga untuk mengembangkan seluruh potensi yang ada pada siswa meliputi perkembangan pengetahuan, penalaran dan perkembangan emosional.

Proses pendidikan akan dapat terlaksana dengan lancar apabila dibantu dengan ketersediaan sarana dan prasarana yang layak disetiap sekolah. Sama halnya dengan pembelajaran yang lain, pembelajaran pendidikan jasmani, olahraga dan kesehatan (PJOK) juga membutuhkan sarana dan prasarana PJOK yang layak disetiap sekolah. Namun menurut (Agustina, 2014) kondisi sebagian besar sekolah di Indonesia tidak memiliki sarana dan prasarana yang cukup layak untuk cabang cabang olahraga yang berkaitan dengan materi pendidikan jasmani dan kesehatan

Pendidikan Jasmani Olahraga dan Kesehatan adalah suatu bidang kajian yang sungguh luas. Definisi PJOK diartikan dengan berbagai ungkapan dan kalimat. Namun esensinya sama, yang bermakna jelas, bahwa PJOK memanfaatkan alat fisik untuk mengembangkan keutuhan manusia. Pendidikan jasmani adalah pendidikan yang berhubungan dengan aktivitas fisik yang dilakukan peserta didik dengan mendesain suatu kegiatan untuk meningkatkan kebugaran jasmani (Cahyati, Nunuk Nur, 2019). Dalam kaitan ini diartikan bahwa melalui fisik, mental dan emosional pun turut terkembangkan, bahkan dalam penekanan yang cukup dalam. Menurut Permendiknas Nomor 22 Tahun 2006 mengungkapkan, PJOK adalah bagian integral dari sistem pendidikan nasional secara keseluruhan, bertujuan untuk mengembangkan aspek kesehatan, kebugaran jasmani, keterampilan berpikir kritis, stabilitas emosional, keterampilan sosial, penalaran, dan tindakan moral melalui aktivitas jasmani dan olahraga.

Sarana dapat diartikan sebagai semua fasilitas yang secara langsung menunjang suatu proses. Menurut kamus besar Bahasa Indonesia (2001:999) dijelaskan bahwa sarana adalah segala sesuatu yang dipakai sebagai alat dalam mencapai maksud dan tujuan. Sarana atau alat sangat penting dalam memberikan motivasi peserta didik dengan sungguh-sungguh sehingga tujuaan aktivitas dapat tercapai. Dalam konteks Pendidikan, sarana Pendidikan misalnya buku, alat praga, alat praktek, dan alat keterampilan.

Sarana pendidikan jasmani adalah alat-alat yang sangat mendukung dalam proses belajar mengajar pendidikan jasmani. (Muhammad, 2017) mengatakan "sarana juga dapat diartikan segala sesuatu yang dapat digunakan dalam pembelajaran pendidikan jasmani mudah dipindah bahkan mudah dibawa. Soepartono (1999/2000: 5), menjelaskan bahwa prasarana olahraga adalah sesuatu yang merupakan penunjang berjalannya suatu proses pembelajaran pendidikan jasmani. Sarana Pendidikan jasmani olahraga dan kesehatan merupakan peralatan yang sangat membantu dalam proses belajar mengajar Pendidikan jasmani. Sarana Pendidikan jasmani pada dasarnya merupakan segala sesuatu yang sifatnya tidak permanen, dapat dibawa kemana-mana atau dipindahkan dari satu tempat ketempat lain. Sarana pendidikan jasmani adalah semua peralatan yang digunakan untuk menunjang 
kegiatan olahraga. Proses pembelajaran pendidikan jasmani jika didukung dengan sarana yang layak dan mencukupi, maka proses pembelajaran akan efektif dan efisien (Khikmah, Akhidatul, 2017)

Alat-alat olahraga biasanya dipakai dalam waktu yang lama (Ratal Wirjasantoso, 1984). Alat akan rusak apabila sering dipakai dalam kegiatan pembelajaran Pendidikan jasmani, sehingga agar alat dapat bertahan lama harus dirawat dengan baik. Prasarana, secara etimologi berarti alat yang tidak langsung untuk mencapai tujuan. Prasarana adalah segala sesuatu yang merupakan penunjang utama terselenggaranya suatu proses usaha, pembangunan proyek, dan lain sebagainya (Kamus besar Bahasa Indonesia, 2001),. Prasarana PJOK pada dasarnya merupakan segala sesuatu yang bersifat permanen. Kelangsungan proses pembelajaran PJOK tidak terlepas dari tersedianya prasarana yang baik dan memadai akan menunjang proses pembelajaran jasmani dengan baik pula.

Prasarana pembelajaran Pendidikan PJOK adalah suatu yang merupakan penunjang terlaksananya suatu proses pembelajaran PJOK (Soepartono, 2000). Dalam pembelajaran PJOK, prasarana didefinisikan sebagai suatu yang mempermudah dan memperlancar proses. Salah satu sifat yang dimiliki oleh prasarana PJOK adalah sifatnya yang relatif permanen atau untuk dipindah. Prasarana PJOK yang dimaksud dalam pendapat tersebut dapat diartikan sebagai prasarana dengan ukuran standar, seperti lapangan bola basket, lapangan tenis, Gedung olahraga (hall), stadion sepak bola, dan stadion atletik. Dalam pembelajaran pendidikan jasmani prasarana diartikan sebagai sesuatu yang mempermudah atau memperlancar proses. Sarana dan prasarana memberikan dampak yang signifikan bagi keberhasilan suatu proses pembelajaran pendidikan jasmani olahraga dan kesehatan (PJOK) di sekolah. Ketersediaan sarana dan prasarana dalam pendidikan jasmani bertujuan untuk memperlancar kegiatan belajar mengajar dan untuk tercapainya tujuan pendidikan yang lebih baik. (Negara, Ike Porwa, 2017)

Kurangnya sarana dan prasarana akan menghambat proses pembelajaran yang nantinya juga akan berdampak kepada hasil belajar siswa. Siswa akan mengantri untuk mendapatkan giliran mencoba atau menggunakan sarana dan prasana PJOK, dengan seperti itu peserta didik merasa bosan dalam melaksanakan proses pembelajaran karena tanpa sadar hal tersebut menyebabkan manipulasi gerak siswa menjadi berkurang. Apabila hal tersebut dilakukan berulang-ulang, kebugaran siswa tidak akan pernah terwujud. Sarana dan Prasarana merupakan sesuatu yang sangat penting dalam keberhasilan pembelajaran PJOK dengan demikian peneliti ingin meneliti Ketersediaan sarana prasarana PJOK di SD Negeri se-Kecamatan Tembuku Kabupaten Bangli.

Kenyataannya SD se-Kecamatan Tembuku masih beberapa sekolah yang sarana dan prasarananya masih kurang. Mereka menggunakan lapangan umum yang digunakan secara bersama-sama karena terbatasnya lapangan yang tersedia disekolah apalagi materi yang diajarkan menuntut menggunakan lapangan yang lebih besar dan berstandar. Minimnya pengadaan sarana seperti alat olahraga yaitu bola, matras, raket dan alat lainnya yang jumlahnya minim sehingga banyak siswa yang dalam proses pembelajarannya kebanyakan pasif, sehingga pembelajaran menjadi tidak efektif. Dengan kenyataan seperti itu, peneliti berusaha mencari kenyataan dari apa yang peneliti lihat yang ada dilapangan sehingga dapat diambil kesimpulan terhadap saran dan prasarana dalam pembelajaran PJOK di SD seKecamatan Tembuku untuk mencapai hasil yang baik bagi peserta didik.

Melihat Permasalah diatas maka perlu diadakannya penelitian keberadaan sarana dan prasarana PJOK di Sekolah Dasar Negeri se-Kecamatan Tembuku Kabupaten Bangli untuk menjadi bahan pertimbangan dalam proses pembelajaran PJOK, dan untuk mengetahui lebih banyak ketersediaan sarana dan prasarana pembelajaran pendidikan jasmani olahraga dan kesehatan (PJOK) dimasing-masing Sekolah Dasar Negeri se-kecamatan Tembuku Kabupaten Bangli. Tujuan yang ingin di capai dalam penelitian ini adalah untuk mengetahui 
ketersediaan dan kondisi sarana dan prasarana dalam pembelajaran PJOK di SD Negeri seKecamatan Tembuku Kabupaten Bangli.

\section{Metode}

Penelitia ini berjenis deskriptif, yaitu penelitian yang bertujuan menjelaskan dan menggambarkan pristiwa secara natural yang dilakukan dengan menganalisis data dan hasil dari data tersebut dengan menggunakan hasil data yang diperoleh dari proses yang sudah berlangsung. Metode deskriftif yang digunakan adalah Pendekatan kuantitatif, pendekatan kuantitatif merupakan salah satu upaya pencarian ilmiah (selentific inquiri) yang didasari oleh filsafat positivisme logika yang beroberasi dengan aturan-aturan yang ketat mengenai logika, kebenaran, hukum-hukum, dan prediksi. Focus penelitian kualitatif dinifinisikan sebagai proses kerja yang berlangsung secara ringkas (Santyasa I Wayan, 2019: 140)

"Populasi berkaitan dengan seluruh kelompok orang, pristiwa, atau benda yang akan menjadi pusat perhatian penelitian untuk di teliti"(Sudaryono, 2016). Menurut Sudaryono (dalam Kurniawan, 2016 : 110) populasi juga dapat dikatakan sebagai wilayah generalisasi yang terdiri dari objek atau subjek yang mempunyai kualitas dan karakteristik tertentu yang ditetapkan oleh peneliti untuk dipelajari kemudian di Tarik kesimpulan. Jadi populasi bukan hanya orang tetapi juga objek dan benda-benda alam yang lain. Populasi dalam penelitian ini adalah seluruh Sekolah Dasar Negeri se-Kecamatan Tembuku Kabupaten Bangli yang berjumlah 29 Sekolah Dasar

Sampel adalah bagian dari jumlah dan karakteristik yang dimiliki oleh populasi tersebut. Bila besar dan peneliti mungkin mempelajari semua yang ada di populasi. Misalnya karna keterbatasan dana, tenaga, dan waktu, maka penelitian dapat menggunakan sampel yang doambil dari populasi itu. Apa yang dipelajari dari sampel itu, kesimpulannya akan dapat diperlakukan untuk populasi. Untuk itu sampel yang diambil dari populasi harus betulbetul representative atau mewakili (Sudaryono, 2016).

Penelitian ini dilaksanakan di SD Se-kecamatan Tembuku. Yang dijadikan sampel dalam penelitian ini terdiri dari 3 gugus dan setiap gugus yang di ambil adalah sekolah inti seperti gugus satu diwakili SDN 5 Jehem, gugus dua SDN 1 Tembuku, dan ugus tiga SDN 6 Peninjoan. Teknik sampling dalam penelitian ini adalah porposif random sampling.

Dalam penelitian ini menggunakan metode survei dengan menggunakan lembar instrument PPJOI sebagai intrumen pengumpulan data untuk mencatat hasil survei yang sudah dilakukan di sekolah.Instrumen pada penelitian ini berpedoman pada PDPJOI

Teknik Pengumpulan data dalam penelitian ini dilakukan dengan cara observasi langsung dalam penelitian ini menggunakan Instrumen Pangkalan Data Pendidikan Jasmani Olahraga Indonesia (PDPJOI). Pada data PDPJOI telah ditentukan nilai total maksimalnya sesuai ms. Excel pada instrument PDPJOI. Pengkategorian pada rekan Ms. Excel dengan rumus yang sudah ada pada rekap instrumen tersebut digunakan untuk mengetaui keberadaan saran dan prasarana yang ada di SD Negeri se-Kecamatan Tembuku kemudian atas bantuan dari guru pendidik jasmani penelitian melihat langsung dan mengisi data dilembar observasi baik yang ada di Gudang maupun tempat lain sesuai dengan lembar observasi yang telah tersusun. 


\section{Hasil dan Pembahasan}

Setelah dilakukan pengambilan data dan mendapatkan hasil data dari masing-masing SD Negeri se-Kecamatan Tembuku Kabupaten Bangli. Dapat dilihat dari Tabel berikut :

Tabel 1. Jumlah Keberadaan Sarana SD Negeri Se-Kecamatan Tembuku Kabupaten Bangli

\begin{tabular}{lcccc}
\hline \multirow{2}{*}{ Nama Sarana } & \multicolumn{3}{c}{ Nama Sekolah } & Jumlah \\
\cline { 2 - 4 } & $\begin{array}{c}\text { SD N 1 } \\
\text { Tembuku }\end{array}$ & $\begin{array}{c}\text { SD N 5 } \\
\text { Jehem }\end{array}$ & $\begin{array}{c}\text { SD N 6 } \\
\text { Peninjoan }\end{array}$ & \\
\hline Permainan dan Olahraga & & & & \\
Bola Besar & 15 & 20 & 19 & 54 \\
Bola Kecil & 6 & 9 & 0 & 15 \\
Atletik & 11 & 20 & 15 & 46 \\
Olahraga Tradisional & 0 & 0 & 0 & 0 \\
Bela Diri & 4 & 10 & 8 & 22 \\
Aktivitas pengembangan & & & & \\
Kekuatan & 0 & 2 & 4 & 6 \\
Daya Tahan & 8 & 10 & 5 & 23 \\
Kelentukan & 0 & 0 & 0 & 0 \\
Kebugaran Jasmani & 12 & 9 & 8 & 29 \\
Aktivitas senam/ritmik & & & & 19 \\
Senam Alat & 8 & 7 & 4 & 16 \\
SKJ/Aerobic & 6 & 10 & 0 & 0 \\
Aktivitas Air & 0 & 0 & 0 & $\mathbf{2 4 9}$ \\
Pendidikanluar Kelas & 10 & $\mathbf{1 0 1}$ & $\mathbf{6 8}$ & \\
\hline$\quad$ Total & $\mathbf{8 0}$ & & & \\
\hline
\end{tabular}

Penelitian ini dilakukan untuk mengetahui jumlah, kondisi dan kualifikasi sarana dan prasarana PJOK di SD Negeri se-Kecamatan Tembuku Kabupaten Bangli. Berdasarkan obsevasi dan pengumpulan data dengan survei berpedoman PDPJOI sarana dan prasarana Pendidikan jasmani di SD Negeri se-Kecamatan Tembuku Kabupaten Bangli.

Jumlah Sarana setiap sarana Pendidikan jasmani yang dimiliki setiap sekolah Dasar Negeri se-Kecamatan Tembuku jumlahnya berbeda-beda. Jumlah keseluruhan sarana Pendidikan jasmani adalah 262, yang terbanyak dari sarana tersebut adalah bola besar, (bola sepak, bola voli, bola basket) dan yang kedua adalah Atletik yang sebanyak 46 buah dan yang ketiga adalah kebugaran jasmani yang sebanyak 29 buah. Sedangkan jumlah keseluruhan sarana Pendidikan jasmani yang paling sedikit adalah SKJ aerobik dan Olahraga tradisional yang sebanyak 16 buah. Sarana yang dimiliki oleh semua Sekolah Dasar Negeri seKecamatan Tembuku adalah Bola sepak, Bola Voli, Bola basket, Tolak Peluru, Cakram, Lembing, body protektor, bola pingpong, bola kasti, nomor dada, pemlampung. Sedangkan yang tidak sama sekali dimiliki oleh SD Negeri se-Kecamatan Tembuku adalah, Pralatan Olahraga tradisional ( Bambu galar, lompat tali, dll. ) dari tabel di atas sekolah yang paling banyak memiliki sarana adalah SD Negeri 5 Jehem yang notabenanya sekolah yang paling dekat dengan pusat Kota Kabupaten Bangli, dan sekolah yang paling sedikit yang memiliki sarana Pendidikan jasmani adalah SD Negeri 6 Peninjoan yang notabenanya sekolah ini terletak sangat jauh dari pusat kota yakni ujung timur dari Kabupaten Bangli Kecamatan Tembuku.

Jumlah Prasarana dapat dilihat bahwa jumlah keseluruhan prasarana di sekolah SD Negeri se-Kecamatan Tembuku Kabupaten Bangli berjumlah 11. Dari masing-masing sekolah jumlah keberadaan prasaranan berbeda-beda yang dapat seperti apa yang dijabarkan 
pada tabel sekolah yang paling banyak keberadaan prasarananya adalah tenis meja, untuk SD Negeri 1 Tembuku memiliki 1 prasaranan tenis meja, sedangkan SD Negeri 5 Jehem dan SD Negeri 6 Peninjoan masing-masing memiliki prasarana tenis meja berjumlah 2. Untuk prasarana atletik hanya dua sekolah yang memiliki prasarana tersebut yaitu SD Negeri 1 Tembuku dan SD Negeri 5 Jehem yang berjumlah untuk SD Negeri 1 Tembuku yaitu 1 dan SD Negeri 5 Jehem 2, dan keberadaan Prasarana yang paling tidak dimiliki oleh sekolah adalah prasarana akuatik seperti kolam renang, hampir semua sekolah di SD Negeri seKecamatan Tembuku Kabupaten Bangli tidak memiliki prasarana akuatik.

Dari hasil tersebut maka didapatkan skor total untuk menentukan kategori sarana dan prasarana di SD Negeri se-Kecamatan Tembuku Kabupaten Bangli, dapat dilihat pada Tabel 2 :

Tabel 2. Total Skor Ketersediaan Sarana dan Prasarana dimasing Masing Sekolah

\begin{tabular}{clccccc}
\hline \multirow{2}{*}{ No } & \multirow{2}{*}{ Nama Sekolah } & \multicolumn{2}{c}{ Jumlah Sarana } & \multicolumn{2}{c}{ Jumlah Prasarana } & \multirow{2}{*}{ Skor Total } \\
\cline { 3 - 6 } & Layak & Rusak & Layak & Rusak & \\
\hline 1 & SD Negeri 1 Tembuku & 63 & 18 & 3 & 6 & 66 \\
2 & SD Negeri 5 Jehem & 81 & 33 & 5 & 4 & 86 \\
3 & SD Negeri 6 Peninjoan & 55 & 13 & 3 & 6 & 58 \\
\hline
\end{tabular}

Dilihat dari Tabel 2 diatas maka dapat kategorikan mengenai ketersediaan sarana dan prasarana PJOK sesuai dengan skor yang sudah di totalkan sehingga di dapat keberadaan sarana dan prasarana PJOK di masing-masing sekolah dengan skor total yang berbeda dengan penjelasan. SD Negeri 1 Tembuku dengan kategori Kurang "D” dengan skor 66, dan SD Negeri 5 Jehem dengan kategori Kurang " $D$ ” dengan skor total 86, sedangkan SD Negeri 6 Peninjoan dengan kategori Kurang "D" dengan skor total 58.

Jadi dengan perolehan skor total dan ketegori yang sudah di jelaskan, maka diketahui bahwa keberadaan sarana dan prasarana yang ada di SD Negeri se-Kecamatan Tembuku Kabupaten Bangli masik dikatakan Kurang. Hasil penelitian ini juga sama dengan penelitian yang dilakukan oleh (Satyawan, 2015) memperlihatkan bahwa secara data yang diperoleh bahwa sarana dan prasarana di Kabupaten Buleleng masih sangat kurang ideal

\section{Simpulan}

Berdasarkan observasi yang telah dilakukan dari penelitian survei sarana dan prasarana PJOK yang dilakukan di SD Negeri se-Kecamatan Tembuku Kabupaten Bangli. Dapat disimpulkan bahwa mengenai sarana dan prasarana yang ada di SD Negeri seKecamatan Tembuku Kabupaten Bangli, terdapat 1 sekolah yang memiliki sarana dan prasarana yang cukup memadai sehingga mampu menunjang proses pembelajaran PJOK itu berlangsung, dan dilihat dari data tabel yang sudah didapatkan pada saat penelitian, dan untuk jumlah sarana yang ada di sekolah masih belum semuanya dimiliki oleh sekolah, dengan kualifikasi rusak lebih sedikit dengan yang layak di gunakan. Untuk prasarana sendiri juga masih banyak sekolah yang belum memiliki prasarna yang menunjang proses pembelajaran PJOK, untuk itu kondisi dan keberadaan sarana dan prasarana yang ada di SD Negeri seKecamatan Tembuku Kabupaten Bangli masih belum memadai

Saran dari hasil penelitian ini yaitu: 1) Bagi pihak sepihak sekolah dan pihak atau instansi terkait dengan diketahuinya jumlah, keberadaan, dan kondisi saran dan prasarana di SD Negeri se-Kecamatan Tembuku Kabupaten Bangli agar dapat menentukan langkan berikutnya, untuk masalah keberadaan sarana dan prasarana PJOK dapat terlaksanakan, agar kegiatan pembelajaran PJOK dapat berjalan dengan baik, 2) Bagi guru pendidkan PJOK penelitian ini dapat digunakan sebagai acuan dalam menentukan langkah dalam perencanaan 
persiapan pembelajaran, serta mendapatkan informasi letak keterbatasan sarana dan prasarana, 3) Bagi peneliti yang ingin melaksanakan penelitian sejenis, penelitian ini dapat di jadikan wacana dan tolak ukur dalam melaksanakan penelian yang sejenis.

\section{Daftar Pustaka}

Agustina, N. (2014). Survei Sarana dan Prasarana Pendidikan Jasmani Olaraga dan Kesehatan di Sekolah Luar Biasa Negeri Kendal dan Sekolah Luar Biasa ABC swadaya di Kabupaten Kendal. Jurnal Of Physical Education and Sport and Recreations, 39(11), 1396-1401.

Cahyati, Nunuk Nur, E. H. (2019). Survei Sarana Dan Prasarana Dalam Pembelajaran Pendidikan Jasmani Dan Kesehatan Di Sekolah Dasar Negeri Di Kabupaten Pasuruan. Gelanggang Pendidikan Jasmani Indonesia, 3(2), 111-120. Retrieved from http://journal2.um.ac.id/index.php/jpj

Khikmah, Akhidatul, M. E. W. (2017). Survei Sarana dan Prasarana Pendidikan Jasmani di Madrasah Tsanawiyah (MTS) Se-Kecamatan Klojen Kota Malang Pada Semester Ganjil Tahun 2017. Indonesia Journal of Sports and Physical Education, 1(1), 12-19. Retrieved from http://journal2.um.ac.id/index.php/jospe/index http://fik.um.ac.id/

Muhammad, H. (2017). Ketersediaan Sarana Dan Prasarana Pembelajaran Pendidikan Jasmani, Olahraga Dan Kesehatan (Studi Pada Sd Negeri Se Kecamatan Batuan Kabupaten Sumenep). Jurnal Pendidikan Olahraga Dan Kesehatan, 5(2), 236-239.

Negara, Ike Porwa, H. N. M. (2017). Ketersediaan Sarana dan Prasarana Pembelajaran Pendidikan Jasmani, Olahraga Dan Kesehatan (Studi Pada Sd Negeri Se-Kecamatan Batuan Kabupaten Sumenep). Jurnal Pendidikan Olahraga Dan Kesehatan, 05(02), 236-239.

Satyawan, I. M. (2015). Survei Sarana dan Prasarana Dalam Pembelajaran Penjasorkes di SMA/SMK/MA Kabupaten Buleleng Tahun Pelajaran 2014/2015, 3(2), 54-67.

Sudarmono, M. (2013). Pengembangan permainan Bavos untuk Pembelajaran Pendidikan Jasmani olahraga dan Kesehatan siswa Sekolah Menengah Pertama. Jurnal Of Physical Education and Sport, 2(1), 175-180.

Sudaryono. (2016). Metode dan Rancangan Penelitian. 